\title{
The Lack of Internal Control and the Solutions in the Execution of Small Enterprise Accounting Criterion in Jilin Province
}

\author{
Lili Wang \\ Changchun University of Finance and Economics \\ Changchun, Jilin 130117
}

\begin{abstract}
When executing Small Enterprise Accounting Criterion, there are problems such as insufficient internal control and low accounting information quality, which have brought negative influence on tax equitableness, risk prevention, and sustainable development. On the basis of discussing the relationship between the execution of Small Enterprise Accounting Criterion and internal control, this paper has analyzed the current situation of the lack of internal control in the execution of Small Enterprise Accounting Criterion in Jilin Province, and meanwhile, put forward that it is requested to reinforce the internal control of small enterprises from several aspects, including adjusting business model, perfecting organizational structure, condensing enterprise culture, broadening managers' horizon, and reinforcing execution capacity, making the execution of Small Enterprise Accounting Criterion more secure.
\end{abstract}

Keywords-Small Enterprise Accounting Criterion; Internal control; Countermeasures

\section{RELATIONSHIP BETWEEN THE EXECUTION AND} INTERNAL CONTROL OF SMALL ENTERPRISE ACCOUNTING CRITERION

In October, 2011, the Ministry of Finance released Small Enterprise Accounting Criterion (CK 2011 [17]), which was executed within the range of small enterprises nationwide since January 1, 2013, and it encouraged small enterprises to execute it in advance.

In July, 2017, the Ministry of Finance formulated the Internal Control Regulations of Small Enterprises (Trial), which was executed since January 1, 2018. It encouraged qualified small enterprises to execute the Basic Regulations about the Internal Control of Enterprises and has also provided relevant matching guidance.

The internal control hysteresis of small enterprises has restricted the valid execution of Small Enterprise Accounting Criterion, and high-qualified accounting information can promote the valid operation of internal control, so Small Enterprise Accounting Criterion and the Internal Control Regulations of Small Enterprises (Trial) are closely connected, and mutually promoted, and have promoted the sound development of small enterprises.

\section{A. The objective for Small Enterprise Accounting Criterion and internal control is the same}

The execution objective of Small Enterprise Accounting Criterion is to improve the accounting information quality of small enterprises, reinforce the internal management of small enterprises, and promote the sustainable development of small enterprises. The internal control objective is to reasonably ensure legal enterprise operation and management, safe assets as well as true and complete financial report and other relevant information, improve operation efficiency and effect, and promote enterprises to realize development strategies. It can be seen that the objective for Small Enterprise Accounting Criterion and internal control is the same.

\section{B. Internal control can ensure the reliable information of Small Enterprise Accounting Criterion}

The financial activities of an enterprise refer to fund raising application and distribution. The reliability, correlation and validity of financial activities should be ensured with internal control. Thus, the internal accounting environment can be improved through implementing internal control in small enterprises, and it is the basic supporting measures for the valid execution of Small Enterprise Accounting Criterion.

\section{Small Enterprise Accounting Criterion and internal control can jointly ensure the accounting information quality}

Small Enterprise Accounting Criterion has normalized the behaviors of accounting confirmation, measurement and report, and is the method and approach for realizing accounting information measurement, and in order to ensure that the accounting information quality is true and legal, it is requested to ensure it through implementing internal control. In order to improve the accounting information quality of small enterprises, ensure the true accounting level, valid financial management level, and the execution of accounting supervision management capacity in small enterprises in place, it is requested to rely on the valid execution of internal control. Meanwhile, high-qualified accounting information and financial management activities can promote and improve the internal control level of small enterprises and ensure the valid operation of internal control. 


\section{LACK OF INTERNAL CONTROL IN THE EXECUTION OF SMALL ENTERPRISE ACCOUNTING CRITERION IN JILIN PROVINCE}

Currently, Jilin Province totally has about 1,400,000 small enterprises, occupying $98 \%$ of the total enterprises in the entire province, and this has created above $60 \%$ economic aggregate in the entire province, absorbed $80 \%$ employment personnel, and provided above $50 \%$ revenues. Small enterprises have become the indispensable important force of Jilin Province in the development of revitalizing the old industrial base of the northeast

In order to truly reflect the execution conditions of Small Enterprise Accounting Criterion, this paper divides the type of small enterprises as per Small Enterprise Accounting Criterion and the Type Division Standard Regulations of SMEs (small enterprise standard stipulated by MIIT [2011] No. 300), and regard partial small enterprises in Jilin Province as the field research object.

The investigation adopts the mode of random sampling. We use QQ group, and WeChat group to conduct online investigation, and offline investigation is conducted through ground visits questionnaire mode.

200 small enterprises in Jilin Province participated in the investigation, and recovered 179 valid questionnaires, and the valid recycling rate of questionnaire is $89.5 \%$. The industrial type for enterprises including the manufacturing industry, construction industry, agricultural industry, transportation industry, retail industry, and catering industry; according to the investigation result, enterprises that have executed Small Enterprise Accounting Criterion can occupy $98.3 \%$ of the total quantity, and enterprises that fail to execute Small Enterprise Accounting Criterion but have executed ASBE can occupy $1.7 \%$. In general, most small enterprises can be executed as per Small Enterprise Accounting Criterion, with good executive force, and the execution proportion has exceeded the expectation.

However, it has been found through the investigation about the internal control execution conditions of 173 enterprises implementing Small Enterprise Accounting Criterion that, the lack in the internal control of enterprises can be mainly reflected in the following aspects:

A. Worries of employees about the understanding degree of "internal control", as shown in the investigation result of Figure 1:

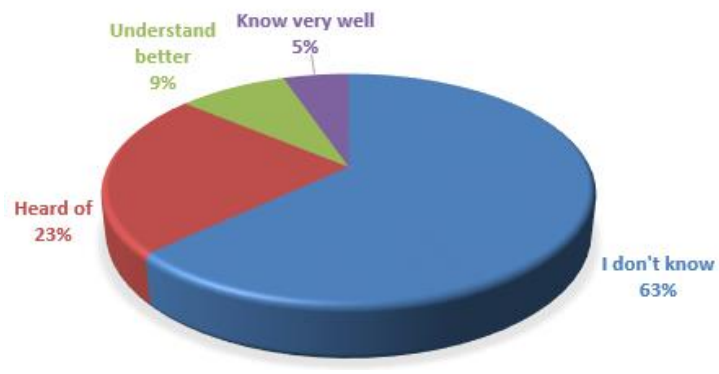

Fig. 1 Knowledge of internal control
As can be seen from the above figure: among the investigated enterprises, merely 5\% senior managers are very familiar with the internal control, and 9\% employees understand a lot about the internal control, 23\% employees know a few about the internal control, and even $63 \%$ employees have no idea about the concept of internal control, let alone how to execute it.

According to the investigation and statistics, $58.3 \%$ small enterprises are family type enterprises. The core management personnel of small enterprises are mostly family members, and due to the existence of nepotism and the fear of hurting others' feelings, it is hard for family members to execute the internal control in place, and the internal control system exists in name only.

\section{B. The organizational structure of small enterprises is unsound, and the distribution of rights and obligations is unbalanced.}

The organizational structure of small enterprises is simple, and generally, one person can hold several concurrent posts, and it is difficult to validly restrict internal control. Some enterprises mix up enterprise accounting and cashier posts, and the cashier will also work at the post of audit, and archive management, etc., and the lack in internal control has hindered the successful implementation of Small Enterprise Accounting Criterion, and cannot provide an accounting environment to ensure true accounting data.

\section{Lack of enterprise culture}

Small enterprises have short establishment time, and fail to build corresponding enterprise culture. Employees of small enterprises lack in cohesion and centripetal force. According to the questionnaire result, among the investigated enterprises, $83.7 \%$ common employees cannot fully understand the operation conditions of the company, and what they can understand are merely responsibilities of the post, and merely $16.3 \%$ employees can understand the responsibility and objective of their department as well as the operation business range of the company, etc. As for the problems faced by the operation management of the company, the long-term strategic objective, development status and other aspects, no one have corresponding understandings.

The lack in enterprise culture has no influence on benefits in surface, but actually, it is bad for the formation of enterprise cohesion and is bad for the long-term development of the company.

\section{The education background for the management layer of the company is relatively low, and the horizon is narrow}

The cultural level for senior managers of small enterprises in Jilin Province, including the president is relatively low, and the accounting personnel with bachelor degree merely occupy $26 \%$. The management layer has relatively low cultural background, which has caused narrow horizon of managers, and the failure in personal learning accumulation and employee training. 
According to the investigation and statistics, $87 \%$ small enterprise managers don't understand about the separation of interlinked duties in the modernized enterprise management system, the internal control and other concepts, and won't apply these management concepts into enterprise management.

As for the training, enterprises organizing the participation of training can occupy $37.1 \%$; among enterprises participating in the training, enterprises that can understand the new criterion through documents and the channel of financial administrative department can occupy $23 \%$; enterprises that can realize less than 3 days of training can occupy $70.32 \%$. It can be seen that, small enterprises don't give employees a good opportunity for continuous study, and the horizon of managers is small, with no attentions being paid to the improvement of study for employees.

$91.7 \%$ management layers of small enterprises express to focus on the economic business of the enterprise, the output, sales and other problems. 93.1\% small enterprise managers express that they fail to pay enough attentions to the internal control management and other problems. The behavior of the management layer of small enterprises for paying too much attention to the short-term effect has neglected the internal control management that can ensure the normal operation of small enterprises.

\section{E. The execution of rules and regulations in small enterprises are insufficient}

According to the investigation analysis, $76.9 \%$ small enterprises have relevant internal control system. But these internal control systems have "two-layer" phenomenon, and the internal control system cannot provide the valid guidance of specific business, and the internal control system fails to obtain valid execution. Meanwhile, small enterprises lack in tracking, feedback and rectification opinions about the execution conditions of rules and regulations, and the internal control system formulated by small enterprises exists in name only.

\section{REINFORCE THE RESEARCH ON INTERNAL CONTROL COUNTERMEASURES OF SMALL ENTERPRISES}

\section{A. Adjust operation mode and increase employees' sense of belonging}

Small enterprises are mostly family type enterprises, and the board of directors and senior management layer are mostly family members, and the shares of small enterprises are mostly mastered by family members, and the internal control exists in name only; on the basis of the existing family operation mode, small enterprises should gradually introduce more non-family members to enter into the senior management layer, and use the opportunity for small enterprises to replacing old managers with new ones, and convert the operation mode of small enterprises into modernized enterprise management mode.

Small enterprises should adopt more performance award methods, such as: issuing performance share, dry share, etc., to increase the sense of belongings for employees, and improve the management level.

\section{B. Perfect organizational structure, and implement accountability system}

Small enterprises have short establishment time and small scale, and in order to save cost, it will rely on rules and regulations and even interpersonal connections to sustain enterprise development; lots of family enterprises adopt family type management mode to govern the enterprise, which will cause unsound organizational structure, weak accountability awareness, and unfulfilled accountability system, etc.

The valid execution of internal control system is to realize the powerful assurance of accountability system; perfect the organizational structure of small enterprises, execute accountability system, reinforce daily inquiry, evaluation and supervision, promote the relevant principals to take a correct attitude towards work, build the awareness of master, increase the sense of responsibility, and ensure the active development of the enterprise.

\section{Pay attention to the condensation of enterprise culture}

Enterprise culture is the foundation for forming management advantages, and is also the source of power for the sustainable development of small enterprises. Internal control is the internal self-inspection and supervision system with the participation of all enterprise personnel. In order to realize good internal control, it is requested to realize the following aspects:

Firstly, it is requested to actively promote sound "human resources policy"; establish talent evaluation system, and then through quantitative evaluation, supervise employees of the enterprise to have loyalty, professionalism, enthusiasm, responsibility, efficiency, communication, team, progressiveness, gratefulness, and other qualities.

Secondly, establish sound talent training system. Enterprises should periodically arrange accounting, internal control and other relevant training, to improve the working capacity and technical skills of employees, increase the team awareness, cooperation and communication capacity, and establish the concept of lifelong learning.

Finally, the enterprise culture has decided the future of the enterprise, and the establishment of "everyone becomes an operator" concept can be good for the valid execution of internal control and increase the centripetal force of the company.

\section{Broaden the horizon of managers, and realize "external introduction and internal training" accounting personnel training policies}

In order to validly implement Small Enterprise Accounting Criterion in enterprises, the management layer of the enterprise should the significance of criterion implementation. In the execution process of the criterion, it is requested to exert the function of publicity and management coordination, and provide necessary conditions for implementing the criterion.

For the direct executor of Small Enterprise Accounting Criterion, the training of financial personnel is necessary, so small enterprises can implement the accounting personnel 
cultivation policy of "externally introduction and internal training", and increase the overall quality of accounting talents in the enterprise:

\section{1) "Externally introduce" high-qualified accounting talents}

As shown in the investigation data, $74 \%$ of the accounting personnel in small enterprises have junior college and below education background, and relatively low academic level. This cannot be separated from the family type management concept, and most financial personnel are trusted followers of the management layer, and the employment "threshold" for the internal personnel isn't high, which has caused low education level of accounting personnel. Thus, when small enterprises hire accounting personnel, it is requested to break through the family type operation concept, and hire personnel with higher education background of finance and accounting as much as possible.

2) "Internally training" should periodically train financial and accounting personnel

Small enterprises should periodically organize training and learning, hire industrial and college experts to teach the accounting personnel the newest financial and accounting knowledge, cultivate the awareness of accounting personnel to actively learn, and make accounting personnel supplement new knowledge at any time, and provide guarantee for the valid execution of Small Enterprise Accounting Criterion.

\section{E. Reinforce the internal control execution of small enterprises}

Validly execute the internal control system of small enterprises, and constantly make adjustment and perfection in the execution process, to better serve enterprise management, and truly exert the function of internal control. Firstly, we must understand the harms incurred by insufficient execution of internal control; secondly, set a special group, and let the manager understanding the operation of all parties of the enterprise as the group leader, coordinate the interests of all parties, improve the execution for the internal control system of small enterprises, gradually and constantly perfect the internal control system of small enterprises, and improve the operation management level of small enterprises.

\section{SUMMARY}

Through investigating and analyzing the execution conditions about Small Enterprise Accounting Criterion in Jilin Province, it can be concluded that: the execution conditions about small enterprise accounting Criterion in Jilin Province has exceeded the expectation, but commonly, the internal control management of small enterprises fails to be implemented in place. The lack in the internal control is bad for the valid execution of small enterprise accounting Criterion, and cannot ensure true and valid accounting information. Thus, this paper suggests that the internal control of small enterprises should be reinforced from several aspects, including adjusting the operation mode, perfecting the organizational structure, condensing enterprise culture, broadening the horizon of managers and reinforcing execution, to make the execution of small enterprise accounting Criterion more secure.

\section{ACKNOWLEDGMENT}

Fund Project: The periodic achievement of Education Department of Jilin Province "13th Five Year Plan" Social Science Project "Small Enterprise Accounting Criterion Operation Countermeasures Research_-Taking the Small Enterprises of Jilin Province as an Example" (Contract No.: JJKH20181356SK)

\section{Date of Reception: July 18, 2018}

About the Author: Lili Wang (1979- ), female, Associate Professor, Master and the research direction is Accounting and Financial Management.

\section{REFERENCES}

[1] Min You: Problems and Countermeasures for Implementing Small Enterprise Accounting Criterion [J], Cooperation Economy, Science and Technology, Period 3, 2018.

[2] Zhixiong Ke: Trial Discussion about the Insufficiencies and Solutions for Implementing Small Enterprise Accounting Criterion [J], Accounting Learning, Period 3, 2017.

[3] Shengli Xiao: Problems and Countermeasures for Executing Small Enterprise Accounting Criterion___-Investigation Based on the Small Enterprises in Hubei Province [J], Green Finance and Accounting, Period 2, 2013.

[4] Yan Feng: Research about the Implementation Problems of Small Enterprise Accounting Criterion [J], Modern Economic Information, Period 15, 2013.

[5] Compiled by ASBE Compilation Audit Committee. Interpretation about the Small Enterprise Accounting Criterion [M]. Lixin Accounting Press, 2018.

[6] Ministry of Finance of PRC. Small Enterprise Accounting Criterion [M]. Economic Science Press, 2011. 